\title{
Effects of Differential Stability on Control of Multi-Joint Coordination in the Upper Extremity: A Torque Component Analysis
}

\author{
Young Uk Ryu, Hwa Kyung Shin \\ Department of Physical Therapy, College of Health Sciences, Catholic University of Daegu, Daegu, Korea
}

\begin{abstract}
Purpose: The purpose of the present current study was to examine control of upper limb multi-joint movements with differential coordination stability. To achieve the goals of the study, torque analyses were utilized to answer questions about how torque components were differed among various elbow-wrist coordination patterns.

Methods: Eight self-reported right-handed college students ( 3 males and 5 females, mean age $=20.6 \mathrm{yr}$ ) were volunteered. The task required participants to rhythmically coordinate the flexion-extension motions of their elbow and wrist with coordination relationship of $0^{\circ}, 90^{\circ}$, and $180^{\circ}$ relative phases between the two joints. Mean relative phase and phase stability (standard deviation of relative phase) were computed to for analysisze of overall coordination performance. To determine the figure out characteristics of torque components in elbow and wrist joints, impulse values of muscle torque (MT) and interactive torque (IT) and MT as a percentage of cycle duration (MTPCD) were analyzed.

Results: Torque results showed that the proximal elbow joint generated motions with mainly muscle efforts regardless of coordination patterns, while the distal wrist joint adjusted the coordination patterns by changing amount of MT. Impulse analyses showed that the least stable $90^{\circ}$ pattern was performed by utilizing a similar coordination strategy of the most stable $0^{\circ}$ pattern.

Conclusion: The present current study suggests that the roles of distal and proximal joints differ in order to achieve various multi-joint coordination movements. This study provides information for use in gives an idea to development of rehabilitation or training programs for to persons with an impaired upper limb motor ability.
\end{abstract}

Keywords: Multi-joint, Coordination, Torque

\section{서 론}

상지(upper extremity)의 기능은 일상생활 동작 수행에 아주 중요하다. 상지의 기능이 제대로 수행되지 않는다면 많은 일상생활 동작에 어 려움을 겪을 것이다. 상지를 사용하는 대표적 일상생활 동작들은 쓰 기(writing), 그리기(drawing), 뻗기(reaching), 던지기(throwing) 등이 있 다. 이러한 일상생활 동작들이 수행될 때, 상지의 관절을 이루고 있는 어깨(shoulder), 팔꿈치(elbow), 손목(wrist) 관절 중 하나의 관절이 아니 라 일반적으로 두 세 개의 관절이 동시에 사용된다. 즉, 대부분의 일 상생활 상지 동작은 다관절(multi-joint) 운동이다.

상지 동작의 이해는 이처럼 여러 관절들의 운동학적 특성(kinesiological characteristics)을 동시에 파악하는 것이 중요하다. ${ }^{2}$ 이를 위해
최근 많은 연구들이 역동역학(inverse dynamics)을 이용한 토크 분석 (torque analysis)을 사용하고 있다. 토크는 축(axis)을 가진 회전 물체 에 발생하는 힘을 말하는데, 사지(limbs)의 움직임은 모두 관절이라 는 축을 중심으로 토크를 발생시키게 된다. 인체의 움직임은 크게 세 가지 힘에 의해 생성된다. 근육의 힘, 중력, 인접관절에서 발생한 힘이 그것이며 이 세가지 힘으로 발생한 토크를 근육토크(muscle torque, MT), 중력토크(gravitational torque, GT), 상호토크(interactive torque, IT)라 한다. 이 세가지 토크의 합으로 사지의 움직임이 발생하며 이를 총토크(net torque, NT)라 한다. 즉 NT=MT+GT+IT 이며, 이를 분석하 여 사지의 움직임이 어떤 힘에 의해 발생하는지 알 수 있다. ${ }^{4}$

현재까지의 상지 다관절 운동 분석에 관한 연구들은 움직임(NT) 은 원위관절(distal joint)에서는 대부분 근육의 힘에 의해 발생되며, 근
Received Jan 12, 2016 Revised Feb 21, 2016

Accepted Feb 21, 2016

Corresponding author Young Uk Ryu

E-mail ryuyounguk@gmail.com
Copylight (C) 2016 The Korea Society of Physical Therapy

This is an Open Access article distribute under the terms of the Creative Commons Attribution Non-commercial License (Http:// creativecommons.org/license/by-nc/3.0.) which permits unrestricted non-commercial use, distribution, and reproduction in any medium, provided the original work is properly cited. 
위관절(proximal joint)에서는 움직임의 성격에 따라 근육의 힘이나 원 위관절에서 발생된 힘(IT)을 적절히 사용한다는 것을 보여주었다.4-9 하지만, 이전 연구들에서 사용된 과제들은 뻗기, ${ }^{5}$ 그리기, ${ }^{6}$ 던지기, ${ }^{7.8}$ 등과 같은 동작들이었다. 이러한 운동 과제들은 훈련을 하지 않고도 쉽게 생성할 수 있는 동작들이다. 다시 말해, 운동 수행이 간단하거나 이미 일상생활에서 사용되고 있는 학습된 동작들에서는 원위관절 의 역할이 매우 중요한 것으로 파악된다. 하지만, 그렇지 않는 동작들 에서는 근위 및 원위관절의 역할이 어떻게 되는지는 아직 밝혀진 바 없다.

본 연구는 상지 다관절 운동을 이용하여 훈련 없이 하기 어려운 협 응 과제를 수행할 때, 원위관절과 근위관절의 토크 특성에 대해 알아 보았다. 이를 위하여 팔꿈치 관절과 손목 관절 사이의 상대 위상 $0^{\circ}$, $90^{\circ}, 180^{\circ}$ 에 대한 협응 과제를 적용하였다. 인체의 협응 운동에 대한 수학적 모델링인 Haken-Kelso-Bunz (HKB) 모델에 따르면 상대위상 $0^{\circ}$ 와 $180^{\circ}$ 는 내재된 협응 패턴으로 별다른 연습 없이도 수행이 쉽게 가 능하나 $90^{\circ}$ 패턴은 아주 불안정하여 많은 연습이 필요한 것으로 밝혀 졌다.10 이 수학적 모델이 예측하는 바는 양손 협응 운동, ${ }^{11}$ 다관절 협 응 운동, ${ }^{12,13}$ 외부 자극과 운동 간의 협응, ${ }^{14-16}$ 협응 패턴의 지각 ${ }^{-17,18}$ 등 의 연구 결과에서도 확인되었다. 연구 가설은 패턴에 상관없이 근위 관절인 팔꿈치관절은 근육이 주요 운동 생성의 힘이 될 것이며, 원위 관절인 손목관절에서는 패턴의 성격에 따라 MT의 사용량이 결정될 것으로 예상된다.

\section{연구방법}

\section{1. 연구대상}

총 8 명의 대학생들 (남자 3 명, 여자 5 명, 평균 나이 20.6세) 이 본 실험에 참가하였다. 실험 프로토콜과 동의서는 Texas A\&M University의 IRB 위원회에서 승인을 받았다. 모든 참가자들은 자발적으로 본 실험에 참여하였으며, 실험에 참여하기 전에 실험 동의서를 읽고 자발적으로 동의를 하였다. 본 실험의 참가자들은 오른손 잡이로 하였으며, 주로 사용하는 손에 대한 검사는 Coren ${ }^{19}$ 의 평가지를 사용하여 판별하였 다. 모든 참가자들은 실험을 마친 후, 교과목 점수를 부여받았다.

\section{2. 실험 과정}

실험 참여자는 좌석 높이가 조절 가능한 의자에 앉아 특수하게 제작 된 실험 기구에 자신의 팔을 고정시켰다(Figure 1). 실험 기구는 하나 의 경첩관절(hinge joint)와 두 개의 팔로 구성되어 있었다. 참여자의 팔꿈치 관절은 경첩관절에 맞추고, 아래팔은 실험 기구의 먼 쪽 팔에 벨크로 $\left(\operatorname{Velcro}^{\circledR}\right)$ 를 이용하여 고정하였다. 참여자의 손에는 막대기를 쥐게 하였다.

참여자의 운동 데이터를 수집하기 위해 6 개의 적외선다이오드
(IRED) 마커를 Figure 1과 같이 부착하였다. 6 개 IRED의 3 차원 공간 좌표(x, y, z)는 OPTOTRAK ${ }^{\mathrm{TM}} 3020$ (Northern Digital, ON, Canada)으 로 수집하였다. OPTOTRAK 3020은 2.5미터 거리에서 $x, y$ 축으로 0.1 $\mathrm{mm}, \mathrm{z}$ 축으로 $0.15 \mathrm{~mm}$ 의 오차를 가지고 있다. 참여자는 카메라 전방 2.5 미터 앞에서 운동 과제를 수행하였다.

참여자의 운동 수행 과제는 팔꿈치와 손목 관절을 동시에 사용하 여 $0^{\circ}, 90^{\circ}, 180^{\circ}$ 의 상대위상이 되도록 움직이는 것이었다. $0^{\circ}$ 패턴은 팔 꿈치 관절과 손목 관절을 동시에 같은 방향으로 움직이는 패턴(굴곡골곡, 신전-신전) 이며, $180^{\circ}$ 패턴은 두 관절의 움직임을 반대 방향으 로 움직이는 패턴 (굴곡-신전, 신전-굴곡) 이다(Figure 2). $90^{\circ}$ 패턴은 $0^{\circ}$ 와 $180^{\circ}$ 패턴의 가운데 상대위상을 가진 패턴이다.

참여자는 $0.75 \mathrm{~Hz}$ 의 속도로 맞춰진 메트로놈에 의해 팔꿈치-손목 의 협응 과제를 수행하였다. 1 회 시도(trial)에 총 8 회의 메트로놈 신호 가 있었다. 실험을 시작하기 전에 참여자는 운동 수행 과제에 대해 실 험자로부터 설명을 듣고 각 패턴 별로 1 회씩의 연습 시도를 시행하였 다. 연습 시도를 끝낸 후, 무작위 순서로 3 개의 협응 패턴을 각각 3 회 씩 수행하였다. 한 패턴이 끝나면 3 분의 휴식이 주어졌다.

\section{3. 데이터 분석}

모든 데이터는 MATLAB' R201la (Mathworks, MA, USA)을 이용하여 처리, 분석되었다. 데이터 분석을 하기 전, 6 개의 IRED로부터 수집된 3 차원 공간 좌표 정보는 Butterworth (2nd order, dual pass cutoff $10 \mathrm{~Hz}$ ) 필터링 처리를 거쳤다. 공간 좌표는 손목과 팔꿈치의 각도와 토크 성 분을 계산하는데 이용되었다. 토크 성분은 NT, MT, IT, GT이며, 다음 은 토크 성분을 구하는 공식이다.

$$
\begin{aligned}
& \text { 손목: } \\
& \mathrm{NT}=\left(I_{d}+R_{d}{ }^{2} M_{d}\right) \ddot{\phi} \\
& \mathrm{IT}=-R_{d} L_{p} M_{d} \operatorname{Cos} \phi \ddot{\theta}_{p}-\left(I_{d}+R_{d}^{2} M_{d}\right) \ddot{\theta}_{p}-R_{d} L_{p} \operatorname{Sin} \phi \ddot{\theta}_{p}{ }^{2} \\
& \mathrm{GT}=-R_{d} M_{d} \operatorname{Sin} \phi_{d} g
\end{aligned}
$$

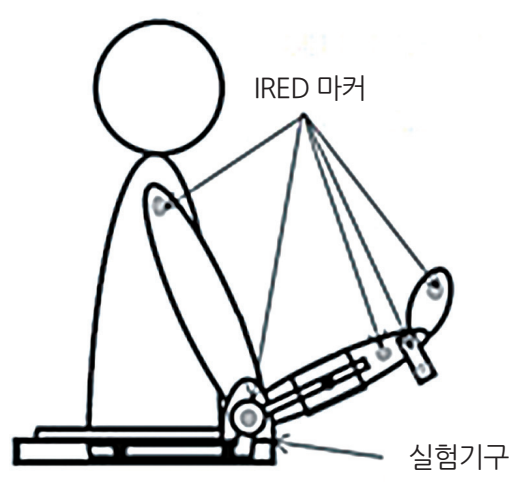

Figure 1. Experimental setup. 
팔꿈치:

$$
\begin{aligned}
\mathrm{NT}= & \left(I_{p}+M_{p} R_{p}^{2}\right) \ddot{\phi}_{p} \\
\mathrm{IT}= & -\left[I_{d}+M_{d}\left(I_{p}^{2}+2 R_{d} L_{p} \operatorname{Cos} \phi\right)\right] \ddot{\phi}_{p}-\left[I_{d}+M_{d} R_{d}^{2}+R_{d} L_{p} M_{d}\right. \\
& \operatorname{Cos} \phi] \ddot{\phi}+R_{d} L_{p} M_{d} \operatorname{Sin} \ddot{\phi}^{2}+2 R_{d} L_{p} M_{d} \operatorname{Sin} \ddot{\phi} \theta_{p} \\
\mathrm{GT}= & -\left(R_{p} M_{p} \operatorname{Sin} \phi_{p}+L_{p} M_{d} \operatorname{Sin} \phi_{p}+R_{d} M_{d} \operatorname{Sin} \phi_{d}\right) g \\
\mathrm{MT}= & \mathrm{NT}-\mathrm{IT}-\mathrm{GT}
\end{aligned}
$$

$\phi_{p}, \phi_{d}$ 는 각각 근위 및 원위 절대관절각도를 나타낸다; $\phi$ 는 $\phi_{d}-\phi_{p}$ 이 며 상대관절각도를 나타낸다; $M_{p}, M_{d}$ 는 각각 근위부(전완) 및 원위부 (손)의 질량을 나타낸다; $R_{p}, R_{d}$ 는 각각 근위부(전완) 및 원위부(손)의 반지름(근위부 끝에서 질량중심사이의 거리)를 나타낸다; $I_{p}, I_{d}$ 는 각 각 근위부(전완) 및 원위부(손)의 관성모멘텀(moments of inertia)를 나 타낸다; $L_{p}, L_{d}$ 는 각각 근위부(전완) 및 원위부(손)의 길이를 나타낸다.

Figure 3은 토크 그래프의 예 (팔꿈치 관절에서 생성된 $0^{\circ}$ 패턴)이 다. NT의 부호와 토크 요소들의 부호가 동일할 경우, 그 토크 성분이 움직임을 이끌어낸 토크이다. Figure 3에서는 NT와 MT는 항상 같은 부호를 가지며, NT와 GT 및 IT는 반대 부호를 가진다. 그러므로 Figure 3에서 보여진 움직임은 MT에 의해 생성되었다라고 해석할 수 있 다. 본 연구에서는 위의 공식을 통해 구해진 토크 성분에 대하여 표 준 평균 임펄스(standardized mean impulse per cycle)와 사이클당 MT 백분율(MT as a percentage of cycle duration, MTPCD)를 계산하였다. 임펄스는 토크가 이루는 커브의 절대값의 합으로 계산하였으며, 이 는 토크의 총량을 나타낸다. 임펄스는 움직이는 물체의 질량에 영향 을 많이 받으므로 피험자의 몸무게로 임펄스 값을 나워서 표준화하

$0^{\circ}$ 패턴 (굴곡-굴곡, 신전-신전)
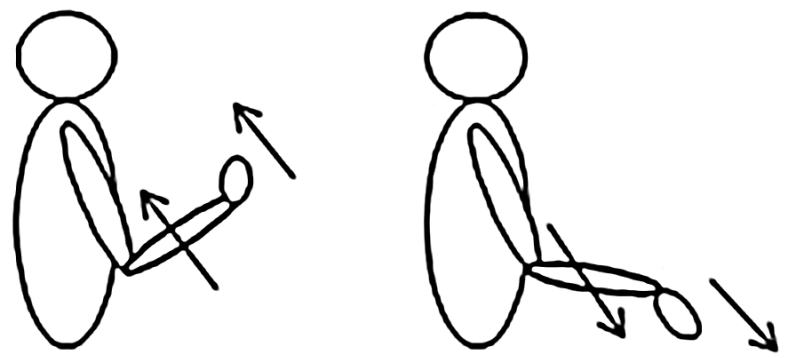

$180^{\circ}$ 패턴 (굴곡-신전, 신전-굴곡)
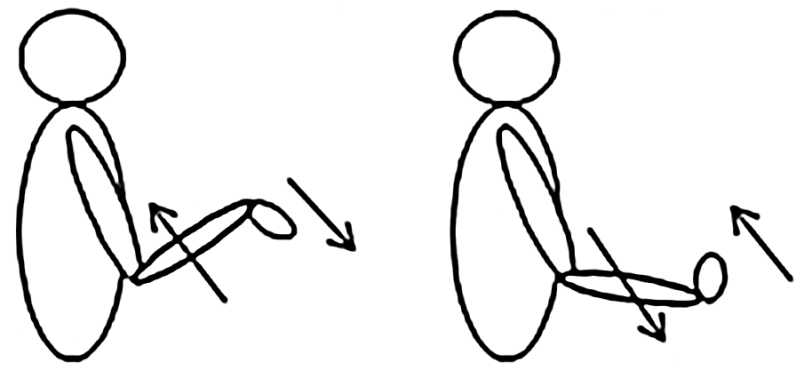

Figure $2.0^{\circ}$ and $180^{\circ}$ coordination relationships between elbow and wrist.
였다. 평균 임펄스를 구하기 위해, 총 임펄스를 사이클의 수로 나누었 다. 표준 평균 임펄스는 MT (ImpMT)와 IT (ImpIT)를 구하였다. $\mathrm{MTPCD}$ 는 움직임에서 MT가 얼마나 NT의 부호(sign)와 일치하였는 지 나타낸 것이다. ${ }^{7}$ 예를 들어, $100 \%$ 일 경우 MT가 움직임 일어난 전 구간에 걸쳐 주요 힘으로 작용했다는 것을 의미한다. 만약 MTPCD 값이 $50 \%$ 라면, MT가 움직임의 $50 \%$ 를 담당했고 나머지 $50 \%$ 는 IT와 GT에 의해 생성되었다는 것을 의미한다. Figure 3의 MTPCD 값은 95\%로 MT가 NT와 동일한 부호를 나타내고 있는 구간이 $95 \%$ 이다.

피험자가 각 패턴의 운동을 얼마나 정확하게 수행했는지를 알아 보기 위하여 평균상대위상(mean relative phase, MRP)을 구하였다. $\mathrm{MRP}$ 는 $\phi_{\mathrm{i}}=\theta_{\text {elbow }}-\theta_{\text {wrist }}$ 로 구하였다. 협응 패턴의 안정성을 알아보기 위하여 상대위상의 표준편차(standard deviation of relative phase, $\mathrm{RPSD}$ )를 구하였다. RPSD는 MRP의 표준편차값으로 값이 작을 수록 안정적을 피험자가 패턴을 수행했다는 의미이다.

\section{4. 통계처리}

MRP, RPSD, ImpMT, ImpIT와 MTPCD를 종속변수(dependent variables)로 하고, 협응패턴 $\left(0^{\circ}, 90^{\circ}, 180^{\circ}\right)$ 을 독립변수(independent variable) 로 하여 일원반복분산분석(1-way repeated analysis of variance)을 실시 하였다. ImpMT, ImpIT, MTPCD는 팔꿈치관절과 손목관절을 나눠서 통계적 검사를 실시하였다. 주효과에서 통계적 유의를 발견하였을 때는 사후검정으로 Tukey 검정을 사용하였다. 모든 통계적 유의 수 준은 알파 $(\alpha)$ 값 0.05 를 기준으로 하였다. 통계처리는 $\mathrm{SAS}^{\circledR} 9.1$ 을 이용 하였다.

\section{결 과}

Table 1에 모든 결과값과 통계결과를 나타내었다. 패턴에 대한 주효과 가 $\mathrm{MRP}$ 에서 발견되었다 $(\mathrm{p}<0.001)$. 사후검사는 3 개의 패턴이 서로 유 의하게 다름을 나타내었다. 이는 피험자들이 팔꿈치-손목 링크를 사

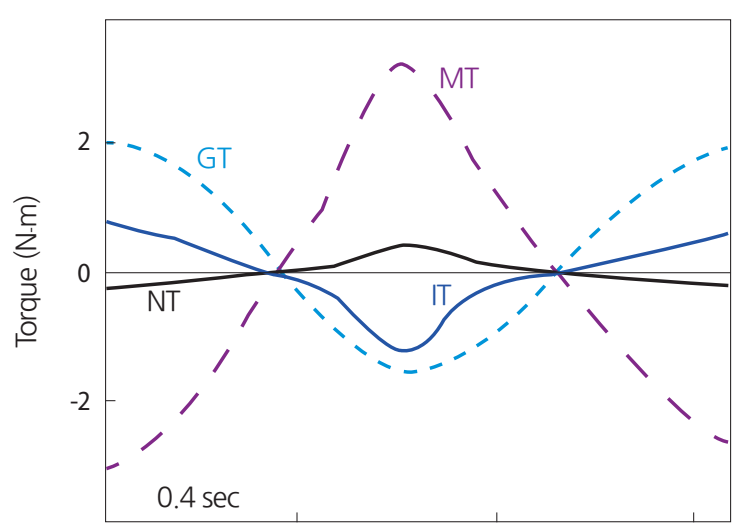

Figure 3. An example of elbow toque profile. 
Table 1. Experimental and statistical results by dependent variables for 3 coordination patterns

\begin{tabular}{|c|c|c|c|c|c|c|c|c|}
\hline & \multirow{2}{*}{ MRP (deg) } & \multirow{2}{*}{ RPSD (deg) } & \multicolumn{2}{|c|}{ ImpMT (N.m) } & \multicolumn{2}{|c|}{ ImplT (N.m) } & \multicolumn{2}{|c|}{ MTPCD (\%) } \\
\hline & & & Elbow & Wrist & Elbow & Wrist & Elbow & Wrist \\
\hline $0^{\circ}(\mathrm{A})$ & $9(7)$ & $20(3)$ & $2.6(0.5)$ & $0.38(0.04)$ & $0.75(0.23)$ & $0.09(0.01)$ & $94(5)$ & $91(7)$ \\
\hline $90^{\circ}(\mathrm{B})$ & $45(31)$ & $41(12)$ & $2.31(0.6)$ & $0.31(0.07)$ & $0.52(0.25)$ & $0.1(0.01)$ & $93(7)$ & $74(12)$ \\
\hline $180^{\circ}(\mathrm{C})$ & $148(18)$ & $34(5)$ & $2.25(0.5)$ & $0.19(0.04)$ & $0.51(0.24)$ & $0.13(0.03)$ & $92(6)$ & $45(8)$ \\
\hline $\mathrm{p}$ & $<0.001$ & $<0.001$ & $<0.01$ & $<0.01$ & $<0.01$ & $<0.01$ & $>0.05$ & $<0.001$ \\
\hline post-hoc & $C>B>A$ & $B>C>A$ & $A>(B=C)$ & $(A=B)>C$ & $A>(B=C)$ & $C>(A=B)$ & $(A=B=C)$ & $A>B>C$ \\
\hline
\end{tabular}

용하여 세 패턴을 서로 다르게 수행했다는 것을 의미한다. RPSD에서 도 패턴에 대한 주효과가 발견되었다 $(\mathrm{p}<0.001)$. 사후검사는 $0^{\circ}$ 패턴에 서 가장 안정적이었고, $90^{\circ}$ 패턴이 가장 불안정하였음을 나타내었다. 이러한 패턴 안정성에 대한 결과는 팔꿈지-손목 관절의 협응 과제 안 정성에 차이가 있었음을 의미한다.

팔꿈치관절에 대한 ImpMT 및 ImpIT 검사에서 패턴에 대한 주효 과가 나타났다 $(\mathrm{p}<0.01)$. 사후검사는 이러한 주효과가 $0^{\circ}$ 패턴이 다른 두 패턴보다 유의하게 더 큰 임펄스를 생성했음을 나타냈다. 손목관 절에 대한 ImpMT 및 ImpIT 검사에서도 패턴에 대한 주효과가 나타 났다 $(\mathrm{p}<0.01)$. 사후검사는 이러한 주효과가 $180^{\circ}$ 패턴이 다른 두 패턴 보다 유의하게 낮은 ImpMT와 큰 ImpIT를 생성했음을 보여주었다.

팔꿈치관절에 대한 $\mathrm{MTPCD}$ 검사는 패턴에 대한 주효과가 나타나 지 않았다( $\mathrm{p}>0.05)$. 이는 패턴에 상관없이 팔꿈치관절은 근육의 힘이 운동 생성의 주 사용하여 운동을 만들어냈음을 의미한다. 반면 손목 관절에 대한 MTPCD 검사는 패턴에 대한 주효과를 나타냈는데 $(\mathrm{p}<0.001)$, 사후검사는 모든 패턴에서 유의하게 서로 다른 값을 나타 냈다. 이는 손목관절에서의 MT 사용량이 서로 다른 패턴을 만들어 주는 역할을 하였다는 것을 의미한다.

\section{고 찰}

본 연구는 토크 요소 분석을 통하여 상지 다관절 운동의 조절에 대 해 살펴보았다. 구체적으로 팔꿈지-손목 관절의 협응 과제 안정성에 따라 원위 및 근위관절의 역할이 어떻게 변화하는지를 살펴보았다. 본 연구 결과는 협응 패턴의 안정성에 상관없이 근위관절인 팔꿈치 관절의 운동은 근육의 힘이 주요한 것으로 밝혀졌으며, 원위관절인 손목관절에서는 근육 힘의 조절이 협응 패턴을 결정하는 것으로 나 타났다. 다음에서는 이러한 연구 결과에 대해 고찰하고 인체 다관절 운동의 조절 및 재활에 주는 암시에 대해 토론하고자 한다.

첫째, 협응 패턴에 상관없이 근위관절인 팔꿈치관절을 움직이는데 $\mathrm{MT}$ 가 주요 힘으로 작용한 시간은 전체 운동 시간의 $90 \%$ 이상을 차 지하였다. 이는 다관절 협응의 안정성에 상관없이 팔꿈치관절에서는 $\mathrm{MT}$ 가 관절을 움직이는 주요한 힘으로 작용했다는 것을 의미한다. 다
시 말해, 협응 패턴의 안정성은 근위관절의 조절에 아무런 영향을 미 치지 못한다는 것을 의미한다. 이러한 본 연구의 발견은 그리기, 던지 기 등과 같은 기본적인 움직임을 이용한 이전의 연구들의 결과와 일 치하는 것이다.-9 이에 덧붙여 본 연구에서는 불안정하여 수행이 어 려운 협응 패턴에서도 근위관절의 역할은 변하지 않는다는 것을 보 여주었다.

둘째, 원위관절인 손목관절에서의 MT 사용은 협응 패턴에 따라 달라졌다. 가장 안정된 패턴인 $0^{\circ}$ 에서 MT가 운동 주기의 $91 \%$ 가량으 로 움직임을 생성한 주요한 토크로 사용되었으며, 임펄스 결과도 손 목에서 가장 큰 MT 에너지를 사용한 것으로 나타났다. 이러한 결과 들은 $0^{\circ}$ 협응 패턴을 만들어 내기 위하여 손목에서 근육의 힘으로 움 직임을 만들어냈다는 것을 의미한다. $180^{\circ}$ 패턴의 경우는 MT가 움직 임 생성 시간의 절반도 사용되지 않았으며, 가장 적은 ImpMT 및 가 장 큰 ImpIT를 나타냈다. 이러한 $180^{\circ}$ 패턴의 결과들은 손목 관절은 근육의 힘보다는 팔꿈치관절에서 생성된 힘, 즉 IT를 더 주요하게 이 용하여 $180^{\circ}$ 협응 패턴을 만들어 냈다는 것을 의미한다. $0^{\circ}$ 와 $180^{\circ}$ 패 턴에 대한 이러한 결과들은 본 연구 방법과 유사한 운동 과제를 사용 한 Dounskaia 등 ${ }^{4}$ 의 연구 결과와 일치한다. 그들의 연구 결과 역시 손 목 관절에서는 $0^{\circ}$ 패턴에서는 근육의 힘이 주요 동력이었으며, $180^{\circ}$ 패 턴에서는 팔꿈치에서 전달된 힘(IT)이주요 동력이었다.

$90^{\circ}$ 패턴의 경우, $\mathrm{MT}$ 는 $0^{\circ}$ 패턴보다 적지만 $180^{\circ}$ 패턴보다는 더 많 은 시간 동안 움직임의 생성을 위해 사용되었다. 특별히, ImpMT와 $\mathrm{ImpIT}$ 데이터의 사후 검정 결과는 $90^{\circ}$ 패턴이 $0^{\circ}$ 패턴과 유사하게 수 행되었음을 나타낸다. 이러한 결과는 피험자가 $90^{\circ}$ 패턴을 생성하기 위해 $0^{\circ}$ 패턴을 활용하여 운동을 수행하였음을 의미한다. MRP 값도 $45^{\circ}$ 로 $180^{\circ}$ 보다는 $0^{\circ}$ 에 근접함을 볼 수 있다. 이렇게 $90^{\circ}$ 패턴의 생성이 $0^{\circ}$ 패턴의 생성과 유사하게 조절된 것은 다음의 두 가지 이유로 설명 될 수 있다. 첫째, $0^{\circ}$ 가 $180^{\circ}$ 패턴보다 더 안정한 패턴이므로 $0^{\circ}$ 패턴을 이용하는 것이 더 유리했기 때문으로 보인다. ${ }^{10}$ 다른 여러 협응 운동 연구에서도 훈련을 하지 않은 상태에서의 $90^{\circ}$ 패턴은 $0^{\circ}$ 패턴에 가깝 게(bias) 생성됨이 관찰되었다.13,20 둘째, 근육의 힘으로 운동을 생성하 는 것이 인접관절에서 전해진 힘으로 운동을 조절하는 것보다 더 쉽 기 때문으로 생각된다. 초보자와 숙련자를 대상으로 한 연구들을 살 
펴보면, 특정 운동 기술의 숙련자일수록 원위관절의 IT 사용량이 많 다. ${ }^{21,22}$ 이러한 결과는 운동 기술 습득 초기에는 원위관절을 근육의 힘으로 조절하다가 숙련이 되면 IT를 더 많이 사용하게 된다는 의미 한다. IT 사용량이 늘어나면 적은 에너지로 운동학적으로 효율적인 운동이 가능한 것이다. 즉, 본 연구 결과에서 $90^{\circ}$ 패턴은 훈련 없이 습 득하기 힘든 협응 패턴이므로, 처음으로 수행하는 대상자들은 근육 의 힘으로 원위관절을 조절하는 것이 더 쉬웠을 것으로 생각된다.

본 연구 결과는 상지 다관절 운동 조절이 근위관절과 원위관절의 역할이 틀리다는 것을 보여주었다. 근위관절은 운동 협응의 난이도 와는 상관없이 근육의 힘을 사용하여 운동을 생성해내었으나, 원위 관절은 운동 협응 형태에 따라 근육의 힘도 다르게 사용한 것을 확인 하였다. 이러한 본 연구의 결과는 상지 다관절 운동 수행의 적절성(efficiency)과 기술성(dexterity)은 운동 수행의 특징이나 성격에 따라 원 위관절의 MT (혹은 IT)의 효율적 이용이 결정함을 의미한다. 특별히, 어려운 협응 동작의 경우(본 연구의 $90^{\circ}$ 패턴), 훈련을 하지 않은 상태 에서는 원위관절은 근육의 힘을 주로 많이 사용하여 생성할 가능성 을 본 연구는 보여주었다. 특정한 운동 기술을 학습하는 초기에 움직 임이 뺏뻣하고 부드러워 보이지 않는 이유는 원위관절에서 근육의 힘을 주로 사용하기 때문으로 이해할 수 있을 것이다. ${ }^{23,24}$

본 연구의 결과는 상지 운동 조절 능력이 저하된 환자들의 상지 기 능 재활에 중요한 이론적 암시를 제공할 수 있을 것으로 생각된다. 즉, 본 연구는 상지 기능 재활의 궁극적 목표가 원위관절의 기술성에 있 음을 암시한다. 구체적으로 설명하면, 재활 초기 혹은 기반은 원위 및 근위관절 모두 근력 강화에 중점을 두어야 할 것으로 생각된다. 증가 된 근력을 바탕으로 기능 향상을 위해서는 원위관절에서의 MT의 역 할을 줄이고 IT 및 GT의 효율성 향상에 중점을 맞추어야 할 것으로 생각되며, 이를 위해서 특정 운동에 따른 과제지향적 움직임(taskspecific movements)을 사용하여 재활하는 것이 중요할 것이다. ${ }^{25,26}$

\section{ACKNOWLEDGEMENTS}

This work was supported by research grants (20131232) from the Catholic University of Daegu in 2013.

\section{REFERENCES}

1. Oh TY, Ha JY, Lee EJ et al. The effects of badminton on the shoulder and its correlation with the shoulder pain and disability index. J Kor Soc Phys Ther. 2013;25:29-35.

2. Galloway JC, Koshland GF. General coordination of shoulder, elbow and wrist dynamics during multijoint arm movements. Exp Brain Res. 2002;142:163-80.
3. Huang L, Liu Y, Wei S et al. Segment-interaction and its relevance to the control of movement during sprinting. J Biomech. 2013;46:2018-23.

4. Dounskaia NV, Swinnen SP, Walter CB, et al. Hierarchical control of different elbow-wrist coordination patterns. Exp Brain Res. 1998;121:23954 .

5. Koshland GF, Galloway JC, Nevoret-Bell CJ. Control of the wrist in three-joint arm movements to multiple directions in the horizontal plane, J Neurophysiol. 2000;83:3188-95.

6. Dounskaia NV, Ketcham CJ, Stelmach GE. Commonalities and differences in control of various drawing movements. Exp Brain Res. 2002; 146:11-25.

7. Hiroshima M, Kudo K, Ohtsuki T. Utilization and compensation of interaction torques during ball-throwing movements. J Neurophysiol. 2003;98:1784-96.

8. Hirashima M, Kudo K, Watarai K. Control of 3D limb dynamics in unconstrained overarm throws of different speeds performed by skilled baseball players. J Neurophysiol. 2007;97:680-91.

9. Debicki DB, Watts S, Gribble PL et al. A novel shoulder-elbow mechanism for increasing speed in a multijoint arm movement. Exp Brain Res. 2010;203:601-13.

10. Haken H, Kelso JAS, Bunz H. A theoretical model of phase transitions in bimanual coordination. Bio Cybern. 1985;51:347-56.

11. Ryu YU, Buchanan JJ. Amplitude scaling in a bimanual circle-drawing task: pattern switching and end-effector variability. J Motor Behav. 2004;36:265-79.

12. Buchanan JJ, Kelso JAS. Posturally induced transitions in rhythmic multijoint limb movements. Exp Brain Res. 1993;94:131-42.

13. Buchanan JJ. Learning a single limb multijoint coordination pattern: the impact of a mechanical constraint on the coordination dynamics of learning and transfer. Exp Brain Res. 2004;156:39-54.

14. Ryu YU, Buchanan JJ. Learning an environment-actor coordination skill: visuomotor transformation and coherency of perceptual structure. Exp Brain Res. 2009;196:279-93.

15. Ryu YU. Learning a single Joint perception-action coupling: A pilot study. J Kor Soc Phys Ther. 2010;22:43-52.

16. Ryu YU, Buchanan JJ. Accuracy, stability, and corrective behavior in a visuomotor tracking task: a preliminary study. PLoS One. 2012;7:e38537.

17. Bingham GP, Schmidt RC, Zaal, FTJM. Visual perception of the relative phasing of human limb movements. Percept Psychophys. 1999;61:24658.

18. Ryu YU. Visual Perception Dynamics of Relative Phase Coordination Pattern with Additional Visual Information Using a Background Grid. The Korean Society for Cognitive Science. 2012;23:409-24.

19. Coren $S$. The lateral preference inventory for measurement of handedness, footedness, eyedness, and eardness. Norms for young adults. Bull Psychon Soc. 1993;31:1-3.

20. Swinnen SP. Intermanual coordination: from behavioural principles to neural-network interactions. Nature Rev Neuro. 2002;3:348-59.

21. Gray S, Watts S, Debicki D et al. Comparison of kinematics in skilled and unskilled arms of the same recreational baseball players, J Sport Sci. 2006;24:1183-94.

22. Furuya S, Osu R, Kinoshita H. Effective utilization of gravity during arm downswing in keystrokes by expert pianists, Neuroscience. 2009;164: 822-31. 
23. Vereijken B, Emmerik REV, Whiting HTA et al. Free(z)ing degrees of freedom in skill acquisition. J Mot Behav. 1992;24:133-42.

24. Mattos D, Schöner G, Zatsiorsky VM et al. Task-specific stability of abundant systems: structure of variance and motor equivalence. Neuroscience. 2015;310:600-15.

25. Schaefer SY, Dibble LE, Duff K. Efficacy and feasibility of functional up- per extremity task-specific training for older adults with and without cognitive impairment. Neurorehab neural repair. 2015;29:636-44.

26. Winstein CJ, Wolf SL, Dromerick AW et al. Effect of a Task-Oriented Rehabilitation Program on Upper Extremity Recovery Following Motor Stroke: The ICARE Randomized Clinical Trial. JAMA. 2016;315:57181. 